\title{
Methodical approach to the estimation of possible energy production by wind and solar power plants using weather station data
}

\author{
Vladislav Shakirov ${ }^{*}$, Bratsk State University, Bratsk, Russia
}

\begin{abstract}
The expediency of using several sources of information on climate factors for estimating the potential of wind and solar energy is substantiated. Specific features of the methodology and developed software for estimating the generation of energy by wind power plants based on weather stations open access data are considered. The possibility of taking into account the results of aerodynamic modeling of the flow of the terrain by the wind flow is realized. The methodology is implemented in the form of a computer program called Wind-MCA. It includes a module for analyzing wind power potential, a module for analyzing wind turbines, an economic analysis module, and a multi-criteria analysis module. Specific features of the methodology and developed software for estimating the generation of energy by solar power plants based on data on the transparency of the atmosphere, temperature and cloudiness are considered. The technique is implemented in the form of a computer program called Sun-MCA. The estimation of the wind energy and solar energy potential of several settlements in the central zone of the Baikal region is carried out taking into account the climate change in the region.
\end{abstract}

\section{Introduction}

In 2017, the world's total installed capacity of wind power plants (WPP) exceeded 539 GW [1], whilst that of the solar power plants (SPP) exceeded 402 GW [2]. Russia boasts a considerable potential for wind and solar power. The technical potential of wind energy in Russia is 2000 million tons of oil equivalents (TOE) per annum; the economic potential is 10 million TOE per annum. The technical potential of solar energy is 2300 million TOE per annum, economic -12.5 million TOE per annum [3]. As of today, Russia operates only twenty 0.1 to $40 \mathrm{MW}$ SPP and six 1 to $35 \mathrm{MW}$ WPP. WPP and SPP potential could be unlocked in the following areas $[4,5]$ :

- areas with high wind or solar power potential;

- areas of decentralized power supply (65\% of the country's territory);

- environmentally vulnerable areas;

- touristic and recreational locations.

The prospects of WPP and SPP construction in Russia are noted in numerous strategic documents. The draft Energy Strategy of the Russian Federation for the Period up to 2035

\footnotetext{
*Corresponding author: mynovember@mail.ru
} 
projects that renewable-source power generation shall increase by more than 20 times. The Territorial Planning Plan of the Russian Federation in the field of energy approved by the Decree of the Russian Government from 11 November 2013 No. 2084-p projects that 16 WPP of a total capacity of 6,060 MW shall be constructed by 2030 .

Return on investments will greatly depend on the accurate estimation of energy resources in the potential locations of WPP and SPP. Analytical inputs can be based on satellite data, weather station data, and reference books on the climate. Each source of data has its pros and cons, see Table 1 .

Table 1. Input sources and their characteristics.

\begin{tabular}{|c|c|c|}
\hline Data & Pros & Cons \\
\hline $\begin{array}{l}\text { Satellite } \\
\text { data }\end{array}$ & $\begin{array}{l}\text { - some databases provide nearly- } \\
\text { worldwide coverage; } \\
\text { - database coverage spans multiple } \\
\text { decades; } \\
\text { - specifics of local terrain and } \\
\text { underlying surface are taken into } \\
\text { account. }\end{array}$ & $\begin{array}{l}\text { - some databases do not cover Russia; } \\
\text { - data resolution: } 1 \times 1 \mathrm{deg} ; \\
\text { - data is averaged to a month; } \\
\text { - low accuracy of data on wind speed in } \\
\text { regions with dissected relief; } \\
\text { - low accuracy of data on solar radiation in } \\
\text { the northern regions; } \\
\text { - low accuracy of data on low-level } \\
\text { cloudiness. }\end{array}$ \\
\hline $\begin{array}{l}\text { Weather } \\
\text { station } \\
\text { data }\end{array}$ & $\begin{array}{l}\text { - up to } 8 \text { raw-data updates per day; } \\
\text { - very high accuracy for locations } \\
\text { adjacent to the station. }\end{array}$ & $\begin{array}{l}\text { - earliest available observation point is dated } \\
2005 \text { or } 2009 \text {, depending on the region; } \\
\text { - low network density in some regions. }\end{array}$ \\
\hline $\begin{array}{l}\text { Reference } \\
\text { books on } \\
\text { the } \\
\text { climate }\end{array}$ & $\begin{array}{l}\text { - long-span measurement data } \\
\text { (1936 to 1980); } \\
\text { - contain data from now- } \\
\text { decommissioned weather stations. }\end{array}$ & $\begin{array}{l}\text { - climatic change of the last decades has } \\
\text { affected multiple parameters; } \\
\text { - data is averaged to a month; } \\
\text { - low network density in some regions. }\end{array}$ \\
\hline
\end{tabular}

Apparently, the most accurate measurements of wind- and solar-power potential can be made by combining these sources. This research uses two sources of data: weather station data and reference books on the climate.

It is advisable to use special software for analysis of renewable energy. Such software is better-developed abroad, as foreign countries boast incomparably larger scale of WPP and SPP commissioning. Russian software is mostly developed under the initiatives of individual research teams trying to solve the specific problems of commissioning WPP and SPP. Use of foreign software in Russia has its constraints, as such software relies on satellite data.

This study uses the author-developed software for WPP and SPP construction efficiency analysis. It will therefore produce an estimate of wind- and solar-power potential of several settlements in the central zone of the Baikal region taking into account the climatic change in the region.

\section{About the Wind-MCA and Sun-MCA software}

Fig. 1 presents the structural diagram of the researcher-developed software suite that consists of two applications, Wind-MCA and Sun-MCA. Below is their description. 


\begin{tabular}{|c|c|}
\hline Wind-MCA & Sun-MCA \\
\hline $\begin{array}{l}\text { 1. Weather station data-based wind- } \\
\text { speed analysis }\end{array}$ & $\begin{array}{l}\text { 1. Calculation of solar radiation using } \\
\text { data on atmospheric transparency of } \\
\text { the climate reference books }\end{array}$ \\
\hline v & $\sqrt{3}$ \\
\hline \begin{tabular}{|l|} 
2. Selection of wind turbine models \\
efficient for the local wind conditions \\
taking into account the weather station \\
data and climate reference books
\end{tabular} & $\begin{array}{l}\text { 2. Accounting for weather station data } \\
\text { on cloudiness in the assessment of } \\
\text { incoming solar radiation }\end{array}$ \\
\hline 2 & $\sqrt{3}$ \\
\hline $\begin{array}{l}\text { 3. Analysis of terrain effects on the } \\
\text { wind speed }\end{array}$ & $\begin{array}{l}\text { 3. Accounting for weather station data } \\
\text { on temperature in the assessment of } \\
\text { electricity generation by SPP }\end{array}$ \\
\hline \multirow{2}{*}{\multicolumn{2}{|c|}{ 4. Analysis of project-specific economic efficiency }} \\
\hline & \\
\hline \multicolumn{2}{|c|}{ 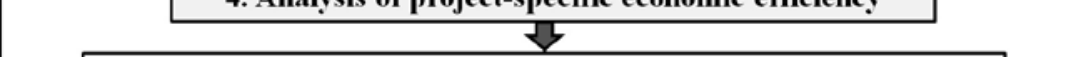 } \\
\hline \multicolumn{2}{|c|}{ 5. Multi-criteria analysis of project efficiency } \\
\hline
\end{tabular}

Fig. 1. Software suite structure.

Wind-MCA is an application that uses weather station data to analyze local wind speeds [6]. Such data are openly accessible online, e.g. at https://rp5.ru. Fig. 2 is a Wind-MCA interface screenshot. It contains two curves, one for the wind speed, and one for the WPP power output for each hour over a month. The power output of a single wind turbine (WT) running as a part of a WPP depends on its performance:

$$
W=\sum_{i=1}^{n} P\left(V_{i}\right) T_{i}
$$

where $P\left(V_{i}\right)$ is the WT output at wind speed $V_{i}$ over time $i, \mathrm{~W} ; T_{i}$ is the duration of time $i$ with the constant speed $V_{i}$, h.

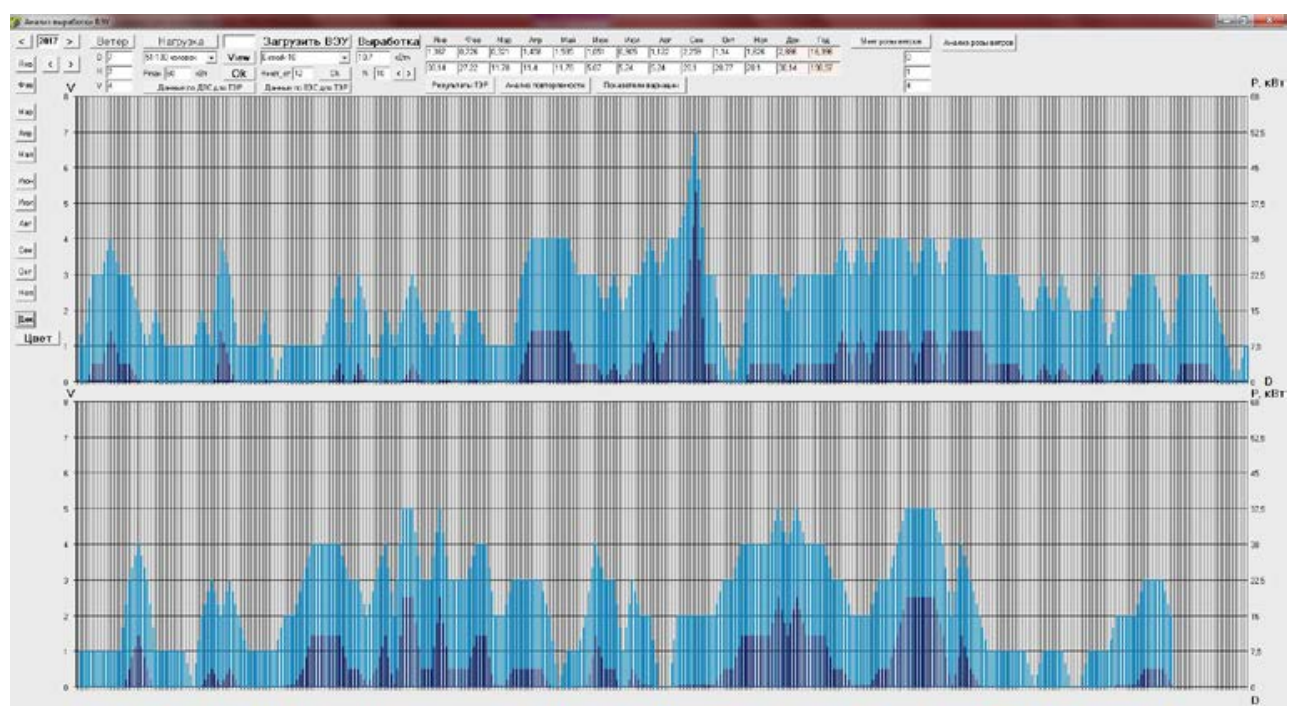

Fig. 2. Wind-MCA interface screenshot. Wind speed and WPP-output curves. 
Another feature of Wind-MCA is that it can analyze the WT power output for separate gradations of the wind speed. To that end, the application can be used to create a WT catalog with their power curves and other technical and economic parameters. Data on the occurrence of various wind speeds can be used to find such sections on the power curves of WT that have the strongest effect on its economic efficiency, see Fig. 3. Analysis of such data could be used to find the most efficient WT models given the local wind specifics.

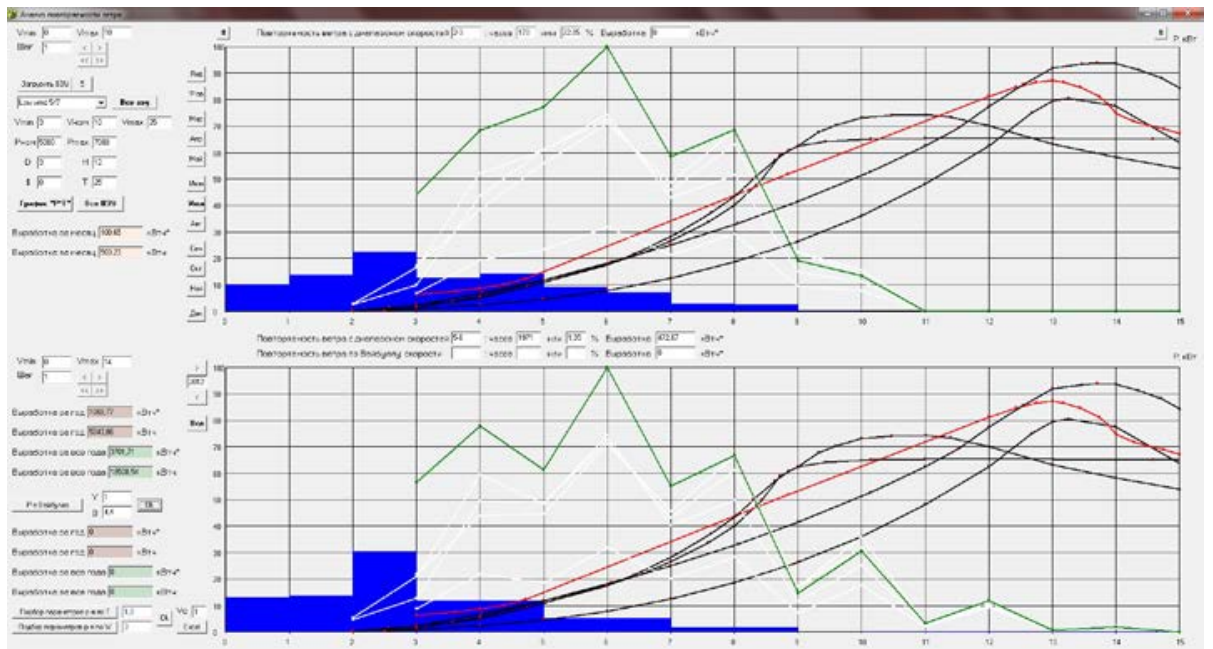

Fig. 3. Wind-MCA interface screenshot. Wind speed occurrence curve, performance and WT output curves.

One important feature of Wind-MCA is the ability to take into account the impact of terrain relief on wind speed. This is done by using third-party programs that allow user to create a three-dimensional terrain model and simulate the wind flow of this model from 8 directions. Simulation results can be expressed and accounted for in the application in the form of terrain-induced wind-speed alteration factors for 8 directions [7].

Sun-MCA is a solar-power analysis application that has a similar interface. The interface can contain the results of estimating the global, beam, diffuse, and reflected reflected radiation arriving at an arbitrarily oriented receiving surface, see Fig. 4.

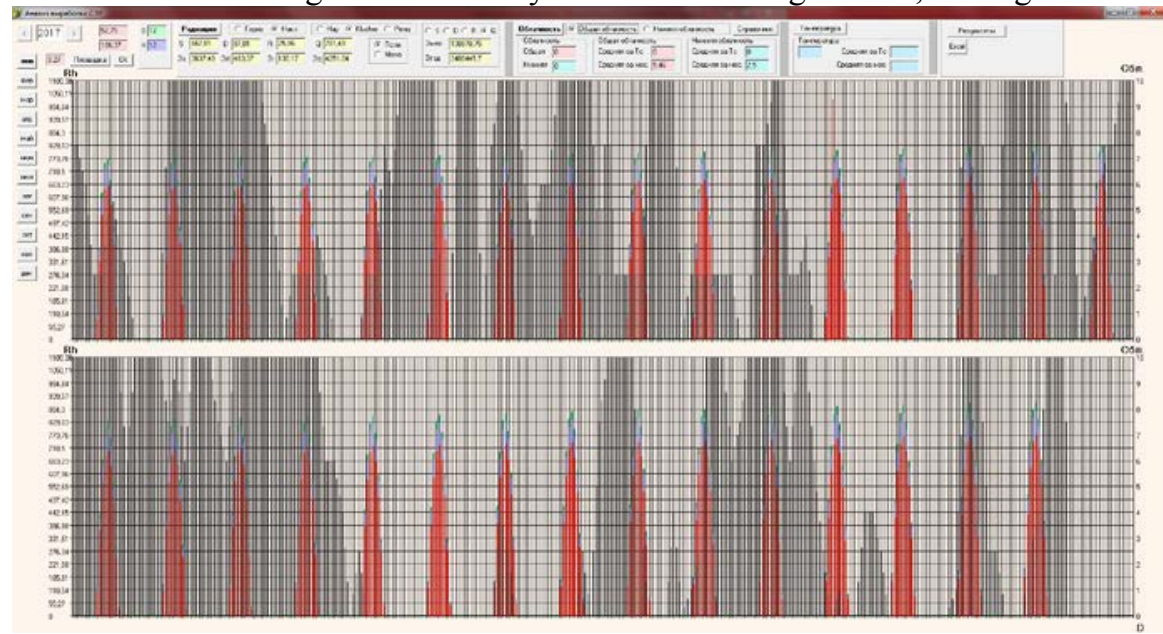

Fig. 4. Sun-MCA interface screenshot. Solar radiation components and total cloudiness curves for each hour over a month 


$$
Q_{t}=S_{t}+D_{t}+R_{t},
$$

where $Q_{t}$ is the global solar radiation received on the inclined surface, $\mathrm{W} \cdot \mathrm{hr} / \mathrm{m}^{2} ; S_{t}$ is the beam solar radiation received on the inclined surface, $\mathrm{W} \cdot \mathrm{hr} / \mathrm{m}^{2} ; D_{t}$ is the sky-diffuse solar radiation received on the inclined surface, $\mathrm{W} \cdot \mathrm{hr} / \mathrm{m}^{2}$; and $R_{t}$ is the ground-reflected solar radiation, $\mathrm{W} \cdot \mathrm{hr} / \mathrm{m}^{2}$.

The value of $S_{t}$ is determined as follows:

$$
S_{t}=S_{n} \cos \theta
$$

where $S_{n}$ is direct solar radiation on the perpendicular to the beams, $\mathrm{W} \cdot \mathrm{hr} / \mathrm{m}^{2} ; \theta$ is the angle of incidence of solar radiation on the surface, rad.

The value of $S_{n}$ is determined according to the Kastrov formula [8]:

$$
S_{n}=\frac{S_{0} \sin \alpha}{\sin \alpha+c}
$$

where $S_{0}$ is insolation at the top atmospheric border, $\mathrm{W} \cdot \mathrm{hr} / \mathrm{m}^{2} ; \alpha$ is the solar angle, rad.; $c$ is the value characterizing the degree of atmosphere clearness.

The atmospheric transparency data are taken from reference books on the climate for 1936-1980. The atmospheric transparency is quite stable and hardly affected by climate change, especially in the North of Russia.

Hay, Klucher, Perez anisotropic models [9, 10, 11] are used for calculating diffuse radiation. Reflected radiation is calculated by means of the isotropic model [12].

The global radiation estimate can be refined by using open-access weather station data. To that end, the application uses total and low-level cloudiness data.

According to the methodology [10]:

$$
Q_{t c}=Q_{t}(1-A \cdot l-B \cdot(n-l)),
$$

where $A, B$ are empirical coefficients that characterize the weakening of global insolation by low-level, as well as by low and medium-level cloudiness; $l$ - low-level cloudiness expressed as a fraction; $n$ - total cloudiness.

According to research [10], for Russia's temperate latitudes $A=0.65, B=0.33$; for Arctic latitudes $A=0,62, B=0,24$. Using the formula (5) for temperate latitudes allows to obtain assessments with a margin of error of up to $10 \%$ for temperate latitudes, and up to $15 \%$ for Arctic latitudes.

Also, the Sun-MCA program uses weather station data on temperature to take into account its effect on the efficiency of photoelectric converters and, accordingly, on the generation of energy by WPP:

$$
W=\sum_{j=1}^{12} Q_{t i} \cdot \eta \cdot F \cdot\left(1-k_{t}\left(t_{j}-25\right)\right),
$$

where $Q_{t i}$ is the global solar radiation received on an inclined surface in month $i, \mathrm{~W} \cdot \mathrm{hr} / \mathrm{m}^{2}$; $\eta$ is the solar photovoltaic system performance coefficient; $F$ is the solar panel area, $\mathrm{m}^{2} ; k_{t}$ is the change rate of the solar module performance coefficient with temperature, relative units; $t_{i}$ is the average daily temperature for month $j$, degrees Celsius.

Analysis of the economic efficiency of WPP and SPP construction investments is based on such values as the discounted payback period and the net present value.

Both applications use multi-criteria analysis to choose WPP and SPP placement sites. Sites are compared by the following criteria: distance to transport and power grid infrastructure; environmental impacts (WPP noise, SPP land requirements, and changes in landscape); popular attitude to various placement options. Multi-criteria utility theory [13] serves as the basis for decision-making. 


\section{Assessment of wind energy potential}

Wind energy potential was estimated for six settlements in the central zone of the Baikal region, see Fig. 5.
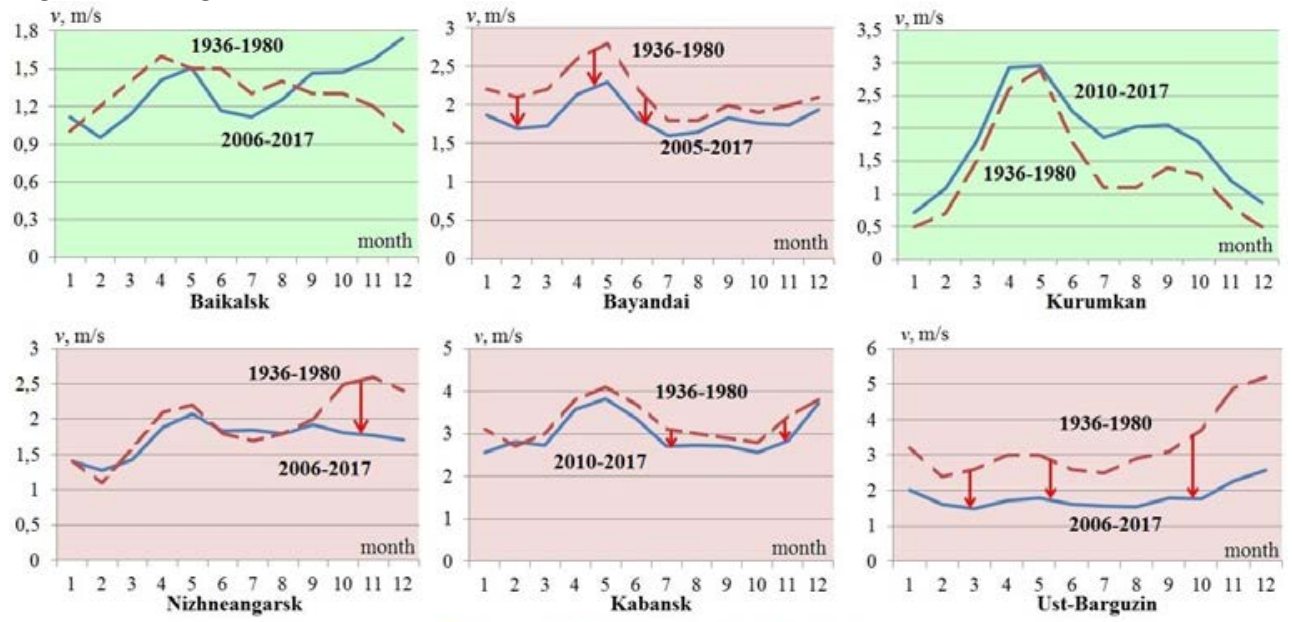

— RP5.RU - - - Reference books on the climate

Fig. 5. Average annual wind speed curves based on ground weather station data and reference books on the climate

For Step 1, we compare the average annual wind speed as given in two information sources (reference books on the climate and open-access weather stations). For four of these settlements, average wind speed is below $3 \mathrm{~m} / \mathrm{s}$, i.e. below the breakaway point for many WT models. Another aggravating factor is the reduction in the average annual wind speed as observed over the last decades in four of the six settlements. This is consistent with the results presented in [14], where it is noted that from 1936 to 2007, wind-speed reduction was noted by 6 out of 10 stations, remained the same for 2 stations, and only increased for 2 stations. Even 1-m/s reduction in the average wind speed has a considerable impact on the WT efficiency, as its power output is a cubic function of wind speed. For further analysis, we select the village of Kabansk in the Republic of Buryatia, as it features the highest average annual wind speed. We analyze five WT models: Exmork 2, Sapsan5000, Low wind 5/7, Exmork 10, Condor-50. For Kabansk, Exmork 2 and Low wind 5/7 are found to be the most technically efficient models, as their performance is better within the 3 to $9 \mathrm{~m} / \mathrm{s}$ range, which occurs relatively frequently in this area. Given quite low electricity prices, the WPP construction payback period exceeds the WT service life. Assuming that the WPP is used as a diesel-fuel replacement, the payback period is 22 years. The general conclusion is that using the wind power in this region is economically inefficient. An exception can be sites with local high wind energy potential due to the influence of the terrain.

\section{Solar energy potential assessments}

Subject to analysis are the settlements of Kurumkan, Narin-Kunta, and Babushkin. For Step 1, we analyze the change in the local cloudiness. To that end, we compare reference books on the climate data for 1936-1980 against weather-station data for 2005-2007. Total cloudiness in Kurumkan was reduced by $7.66 \%$, while the low-level cloudiness was reduced by $44.7 \%$. In Narin-Kunta, the total cloudiness increased by $13.58 \%$ while the lowlevel cloudiness was reduced by $2.97 \%$. In Babushkin, total and low-level cloudiness 
increased by $2.99 \%$ and $18.15 \%$, respectively. The cloudiness is one of the most significant factors affecting the incoming solar radiation, which is why using weather station data results in a considerably better accuracy compared to using reference books on the climate only. Table 2 presents the estimates of incoming solar radiation, photovoltaic-converter outputs, and the discounted payback period for SPP projects.

Table 2. SPP construction efficiency estimates.

\begin{tabular}{|l|c|c|c|}
\hline Settlement & Kurumkan & Narin-Kunta & Babushkin \\
\hline Latitude & 54.15 & 52.75 & 51.72 \\
\hline Average annual atmospheric transparency & 0.80 & 0.79 & 0.78 \\
\hline $\begin{array}{l}\text { Total solar radiation received by an inclined } \\
\text { surface under clear sky, kW·h/m }{ }^{2} \text { per annum }\end{array}$ & $2,522.81$ & $2,519.33$ & $2,500.46$ \\
\hline Average annual total cloudiness & 6.40 & 6.73 & 6.84 \\
\hline Average annual low-level cloudiness & 1.20 & 2.39 & 3.56 \\
\hline $\begin{array}{l}\text { Total solar radiation received by an inclined } \\
\text { surface under clouded sky, } \mathrm{kW} \cdot \mathrm{h} / \mathrm{m}^{2}\end{array}$ & $1,886.71$ & $1,740.65$ & $1,649.67$ \\
\hline $\begin{array}{l}\text { SPP power output as affected by temperature, } \\
\mathrm{kW} \cdot \mathrm{h} / \mathrm{m}^{2} \text { per annum (six } 250-\mathrm{W} \text { solar panels) }\end{array}$ & $3,442.45$ & $3,180.47$ & $2,996.90$ \\
\hline $\begin{array}{l}\text { Discounted payback period } \\
\text { when used as a diesel-fuel replacement, years }\end{array}$ & 23 & 25 & 27 \\
\hline
\end{tabular}

The settlements in the Table 2 are listed in the decreasing-latitude order. However, SPP outputs are higher for settlements farther in the North. This signifies the importance of taking into account the cloud-cover and atmospheric transparency factors, both of which are better in the settlements closer to the North. Ultimately, it is these two factors that affect the payback period within two years.

\section{Conclusions}

When analyzing the efficiency of WPP and SPP construction investments, one has to estimate the potential of such energy sources. It is advisable to combine various input data sources for a more accurate assessment. The author-developed applications Wind-MCA and Sun-MCA use open-access ground weather station data as well as reference books on the climate. This allows taking into account the climate change of the last decades as it affects such significant parameters as wind speed, cloudiness, and temperature.

Wind-power potential analysis shows that wind speeds in the central zone of the Baikal region rarely exceed $3 \mathrm{~m} / \mathrm{s}$; climate change brings about lower average annual wind speeds. Wind power plants can only be efficient if placed in such locations where terrain induces higher wind speeds. The area boasts high solar-power potential; however, relatively low electricity prices mean that solar power cannot compete against conventional powergeneration technologies. Only remote low-power consumers could make an exception for solar power. Changes in cloud cover observed over the last decades mean that this factor must be taken into account when estimating the incoming radiation on the basis of weather station data. 


\section{References}

1. GWEC Global wind report 2017. http://gwec.net/publications/global-wind-report-2/ (Accessed 03.07.2018)

2. Renewables 2018 Global Status Report http://www.ren21.net/gsr2018/pages/tables/tables/\#Table_R1 (Accessed 03.07.2018)

3. Resources and efficiency of renewable energy use in Russia / Edited by P.P. Bezrukikh. SPb. Nauka, 314 p. (2007).

4. I.Yu. Ivanova, B.G. Saneev, T.F. Tuguzova, N.A. Khalgaeva, Renewable Energy as one of the Directions of Reducing Anthropogenic load in the Central Environmental Zone of the Baikal Natural Territory. Geography and Natural Resources, No. 3, pp. 8690 (2016).

5. B.G. Saneev, I.Yu. Ivanova, T.F. Tuguzova, Renewable Sources of Energy in the Regional Energy Programs in the East of Russia: Prerequisites and Rational Scope // Energetik, No. 3, pp. 6-9 (2014).

6. I.Yu. Ivanova, D.D. Nogovitsyn, T.F. Tuguzova, V.A. Shakirov, Z.M. Sheina, L.P. Sergeyeva, Factors Affecting the Wind Resource Utilization Efficiency in the Energy Sector of the Sakha Republic // Proceedings of the Russian Academy of Sciences. Power Engineering, No. 1, pp. 84-92 (2017).

7. V.A. Shakirov, A.Yu. Artemiev, Wind Farm Siting Using Computer Modeling of Terrain Relief and Wind Flow // Proceedings of Irkutsk State Technical University, Vol. 21, No. 11 (130), pp. 133-143 (2017).

8. S.I. Sivkov, Methods of calculating solar-radiation characteristics. Gidrometeoizdat, Leningrad, P. 234 (1968).

9. T.M. Klucher, Evaluation of Models to Predict Insolation on Tilted Surfaces, Solar Energy, Elsevier, Vol. 23, No. 1, pp. 111-114 (1979).

10. J.E. Hay, Calculation of Monthly mean Solar Radiation for Horizontal and Inclined Surfaces, Solar Energy, Elsevier, Vol. 23, No. 4, pp. 301-307 (1979).

11. R. Perez, R. Stewart, C. Arbogast, R. Seals, T. Scott, An Anisotropic Hourly Diffuse Radiation Model for Sloping Surfaces, Description, Performance, Validation, Site Dependency evaluation, Solar Energy, Elsevier, Vol. 36, No. 6, pp. 481-497 (1986).

12. C.C.Y Ma, M. Iqbal, Statistical Comparison of Models for Estimating Solar Radiation on Inclined Surfaces, Solar Energy, Vol. 31, No. 3, pp. 313-317 (1983).

13. A. Yu. Artemyev, V.A. Shakirov, T.N. Yakovkina, Criteria-based Choice of Areas for Siting the Wind Power Plants // Systems. Methods. Technologies. Vol. 31 No 3. pp. 116-122 (2016).

14. A.V. Meshcherskaya, V.A. Obyazov, E.G. Bogdanova, V.M. Mirvis, B.M. Ilyin, N.I. Snitsarenko, M.P. Golod, A.A. Smirnova, A.I. Obyazova, The Climate Change at Zabaikalye during the Second Part of XX century with the Observation Data and Expected Changes at the First Quarter of the XXI Century, Proceedings of Voeikov Main Geophysical Observatory, Vol. 559. pp. 32-57 (2009). 